\title{
Gestão de competitividade e políticas públicas de formação de mão-de-obra: o caso Centro Paula Souza*
}

\author{
Leonardo Trevisan** \\ Elza VEloso***
}

SuMÁrio: 1. Introdução; 2. Descrição do objeto de pesquisa; 3. Conteúdo da pesquisa; 4. Conclusões.

Summary: 1. Introduction; 2. The object of the research; 3. Content of the research; 4. Conclusions.

Palavras-CHAVE: qualificação; competitividade; seleção por mérito.

KEY WORDS: qualification; competitiveness; merit-based selection.

Os trabalhadores mais jovens são os mais atingidos pela incompatibilidade entre o tipo de oferta e o perfil da demanda de mão-de-obra de padrão médio de qualificação. Há carência de estudos quanto à mão-de-obra operacional, fator relevante de competitividade. Os objetivos deste artigo são investigar origens e expectativas da clientela de escolas técnicas, identificar motivos das escolhas profissionais e avaliar as políticas públicas que buscam equilíbrio entre o conhecimento adquirido na escola e o exigido no mercado. A sustentação teórica da pesquisa está nos trabalhos de Naville, Maslow e Alderfer (quanto a motivações), adotando o modelo de Meister

\footnotetext{
*Artigo recebido em set. 2006 e aceito em jun. 2007.

** Professor titular do Departamento de Economia e do Programa de Estudos Pós-Graduados em Administração da PUC-SP. Doutor pela USP com pós-doutoramento pela Universidade de Londres. Autor de vários livros, o mais recente deles Educação e trabalho: as receitas inglesas na era da incerteza. Endereço: Rua Morgado de Mateus, 482, ap. 91 - CEP 04015-051, São Paulo, SP, Brasil. E-mail: ltrevisan@espm.br.

*** Mestre em administração pela PUC de São Paulo e doutoranda em administração na FEAUSP. Atua como consultora técnica pela FIA na pesquisa "As melhores empresas para você trabalhar". Professora da pós-graduação e graduação da Unicid e da pós-graduação da FMU. Endereço: Rua Cayowaá, 1366, ap. 103 - CEP 05018-001, São Paulo, SP, Brasil. E-mail: elzafr@usp.br.
} 
para avaliar vantagens competitivas. As entrevistas qualitativas com grupos de professores mostraram insatisfação com a política pública de seleção por mérito, enquanto as entrevistas com alunos constataram que as políticas públicas de formação técnica não atendem expectativas discentes. As trajetórias profissionais analisadas apresentam certa distância com estas expectativas. As entrevistas com os responsáveis por seleção e contratação das empresas do setor em que a clientela escolar é formada demonstraram fragilidade de vínculos entre a escola e a empresa, com os bancos eletrônicos de currículos alcançando prioridade ante a oferta da clientela da escola técnica.

Competitiveness management and public policies for workforce qualification: the case of the Paula Souza Center

Younger workers are the most affected by the incompatibility between labor offer and the demand for a medium standard qualification. There is a great need for studies on the operational workforce, which is a relevant competitiveness factor. This article's objectives are to investigate backgrounds and expectations from technical school student bodies, to identify motives for particular professional choices, and to evaluate public policies which seek a balance between school-acquired knowledge and expected knowledge in the workplace. The research found theoretical bases on previous work by Naville, Maslow and Aldefer (concerning motivation), adopting Meister's model for evaluating competitive advantages. The qualitative interviews with groups of teachers showed dissatisfaction regarding public policies of merit-based selection, while interviews with students proved that public policies for technical development do not meet their expectations. The interviews with the personnel responsible for selecting and hiring in companies which have students as their clients showed fragile ties between the schools and the companies, with precedence of electronic résumé databases over technical school clients.

\section{Introdução}

A incompatibilidade entre a oferta e o perfil da demanda por trabalhadores qualificados no mercado de trabalho atinge especialmente as faixas etárias mais jovens. Pesquisa da Fundação Seade (2001) demonstra que na década de 1990 ocorreu o recuo de $26 \%$ na participação dos jovens entre 15 e 24 anos no mercado de trabalho paulista. A redução da oferta de postos foi acompanhada por forte pressão por capacitação da força de trabalho, especialmente nas faixas etárias mais baixas. Curiosamente, há demonstrações de carência e ociosi- 
dade no preenchimento de postos de trabalho de qualidade em alguns setores econômicos. Há, portanto, desemprego de mão-de-obra jovem e, ao mesmo tempo, em setores determinados, intensa busca por novos talentos - do operacional ao executivo.

Os estudos na área de administração de empresas têm se preocupado nos últimos anos em compreender o processo de gestão de carreiras da mãode-obra de perfil executivo - o sucesso dos convênios para trainees ou os bem-sucedidos programas de formação via "empresas júnior" são a maior evidência desse fato. A mão-de-obra operacional — porque hoje não é mais possível o uso do pejorativo chão-de-fábrica — que demanda qualificação técnica e é fator básico de competitividade, ainda não recebeu nos estudos acadêmicos a suficiente e necessária atenção.

O Centro Paula Souza — instituição do governo estadual paulista que tem como objetivo essencial compatibilizar a formação técnica com as necessidades das empresas por recursos humanos qualificados, é responsável por uma rede composta de mil escolas de formação profissionalizante, atendendo a mais de 1 milhão de alunos em todas as regiões do estado.

Para analisar o equilíbrio e os fatores de tensão entre a oferta e a demanda por mão-de-obra qualificada de nível médio, foi realizada pesquisa com os seguintes objetivos:

v investigar as origens e expectativas da clientela ingressante no ensino técnico;

v identificar os aspectos subjetivos das escolhas profissionais do corpo discente do ensino técnico;

v avaliar o equilíbrio entre o conhecimento adquirido e o conhecimento exigido, comparando os padrões de formação previstos pelas empresas e os perfis operacionais oferecidos pelas políticas públicas de formação e capacitação de mão-de-obra técnica.

O objetivo deste artigo é, portanto, apresentar os resultados iniciais alcançados pela investigação, no universo de pesquisa selecionado.

\section{Descrição do objeto de pesquisa}

Para analisar as variáveis referentes ao jovem no mercado de trabalho produto do perfil da oferta algo desconectada das exigências da demanda cada um dos objetivos da pesquisa foi atribuído a um núcleo específico de observação: 
v primeiro núcleo - referente à origem e expectativas da clientela ingressante, priorizou o contato com a direção e o corpo docente das escolas técnicas;

- segundo núcleo - referente à identificação de aspectos subjetivos, procurou identificar as escolhas pessoais e profissionais dos alunos do ensino técnico;

v terceiro núcleo - referente à avaliação do equilíbrio entre conhecimento adquirido e exigido, comparou padrões técnicos exigidos pelas empresas com o conteúdo ministrado nos laboratórios das instituições de ensino técnico.

\section{Procedimentos metodológicos}

Com base na classificação de Selltiz e outros (1967), as pesquisas são divididas em três tipos: os estudos exploratórios, os descritivos e os estudos para verificar hipóteses causais. Na pesquisa para este artigo utilizamos predominantemente o método de estudo de pesquisas exploratórias, que tem como objetivo proporcionar visão geral sobre fatos e normalmente são realizadas quando o tema é pouco explorado e torna-se difícil a formulação de hipóteses precisas e operacionalizáveis. Habitualmente, esse tipo de pesquisa envolve "levantamento bibliográfico, entrevistas não padronizadas e estudos de caso" (Selltiz et al., 1967:62).

Gil (1999:26) define o método científico como "o conjunto de procedimentos intelectuais e técnicos adotados para se atingir o conhecimento". Aqui o modelo escolhido para guiar o método foi o indutivo. Nesse modelo metodológico parte-se do particular e coloca-se generalizações, posteriormente ao trabalho de coleta de dados. Ainda de acordo com Gil (1999:28) "a generalização não deve ser buscada aprioristicamente, mas constatada a partir da observação de casos concretos suficientemente confirmadores dessa realidade".

O método de pesquisa envolve a escolha de "procedimentos sistemáticos" (Richardson, 1999:70). Os procedimentos escolhidos resultam em pesquisas qualitativas ou quantitativas. O método quantitativo, que busca coerência com o tipo de pesquisa descritiva, foi utilizado somente no levantamento dos dossiês para identificação da origem dos alunos das escolas selecionadas. O método qualitativo, coerente com o tipo de pesquisa exploratória, foi prioritariamente utilizado com o objetivo de ampliar a visão sobre a evolução da formação profissional, correlacionando-a com a oferta de políticas públicas de formação de mão-de-obra e com a demanda de setor econômico específico. 


\section{Amostragem}

A amostragem "só ocorre quando a pesquisa não é censitária, isto é, não abrange a totalidade dos componentes do universo, surgindo a necessidade de investigar apenas uma parte dessa população" (Lakatos e Marconi, 1992:108). Segundo Selltiz e co-autores (1987:84), o processo de amostragem ocorre obedecendo a seguinte divisão: probabilística e não-probabilística. A amostragem probabilística torna possível a especificação da probabilidade de cada elemento da população ser incluído na amostra. Já na não-probabilística "não há maneira de estimar a probabilidade que cada elemento tem de ser incluído na amostra, e não há segurança de que todo elemento tenha alguma chance de sê-lo".

$\mathrm{Na}$ pesquisa proposta a amostragem será não-probabilística, que tem como principais vantagens "conveniência e economia". Nesse tipo de amostragem é possível escolher entre três tipos de amostra: amostras acidentais, amostras por cotas e amostras propositais (Selltiz et al.,1987:85). A pesquisa qualitativa foi realizada utilizando-se amostra proposital. Nesse tipo de amostra "podemos escolher com cuidado os casos que devem ser incluídos na amostra" (Selltiz et al., 1987:88).

Na pesquisa qualitativa "a informação coletada pelo pesquisador não é expressa em números, ou então os números e as conclusões neles baseadas representam um papel menor de análise" (Tesch, citado por Moreira, 2002:17). Entre os métodos mais apropriados para a coleta de dados estão "entrevistas abertas, observação participante, análise documental (...), estudos de caso, história de vida etc." (Moreira, 2002:17). Assim, para a coleta de dados de natureza qualitativa foram utilizadas entrevistas. Os roteiros foram elaborados com base em entrevistas semi-estruturadas, tanto individuais quanto em grupos de observação. Nesse tipo de entrevista, apesar da ordem predeterminada das questões, “outras questões podem ser levantadas, dependendo das respostas dos entrevistados, ou seja, podem existir questões suplementares sempre que algo de interessante e não previsto na lista original de questões aparecer" (Gil, 1999:55).

\section{Análise dos dados}

$\mathrm{Na}$ análise dos resultados da pesquisa foi importante definir a maneira como os dados qualitativos seriam tratados após o levantamento.

$\mathrm{Na}$ interpretação das entrevistas foi utilizada a análise de conteúdo, que permitiu "obter, por procedimentos sistemáticos e objetivos de descrição do 
conteúdo das mensagens, indicadores da inferência de conhecimentos relativos às condições de produção/recepção (variáveis inferidas) destas mensagens" (Bardin, 2003:42). Segundo Bardin, esse método é constituído por "um conjunto de técnicas de análise das comunicações". É importante considerar também que, condizentes com esse método de análise, podem ser utilizadas as seguintes técnicas para a exploração do material resultante de entrevistas: análise categorial, análise de avaliação, análise de enunciação, análise de expressão, análise das relações e análise do discurso (Bardin, 2003). Na presente pesquisa foi priorizada a técnica da "análise do discurso".

\section{Universo pesquisado}

Foram pesquisadas duas unidades do Centro Paula Souza: Escola Técnica Estadual Professor Aprígio Gonzaga e Escola Técnica Estadual Martin Luther King, ambas na Zona Leste de São Paulo, nos bairros Penha e Tatuapé, respectivamente. Essas duas escolas foram escolhidas pelo vínculo com o setor eletroeletrônico, área de telefonia, já que ambas oferecem cursos com conteúdos curriculares compatíveis com esse setor de atividade.

\section{Perspectivas teóricas}

Há um histórico de tensões entre organização escolar e mercado de trabalho. Essas tensões são ainda mais profundas quando se contrapõem sistemas educativo e produtivo. A formação profissional é uma espécie de escoadouro natural dessas tensões presentes na escola e na empresa. Este artigo, por meio de pesquisa, procurou captar a trajetória da formação das expectativas profissionais e a construção de escolhas por intermédio da "ação educativa"; por último, contrapôs a expectativa construída com a demanda real. Esse tema teve em Pierre Naville um precursor. O questionamento essencial de Naville sobre essa tensão escola/empresa, formulado desde os anos 1950, foi além do duelo entre "formação geral e formação profissional" procurando, por meio do foco na oposição entre cultura e profissionalização, avanços na visão de que há uma hierarquia "tradicional" entre ensino geral e ensino técnico. Naville (1963:12) priorizou em sua perspectiva teórica a questão do "movimento na sociedade" para revisar padrões de hierarquia entre ensino geral e técnico.

Essa raiz teórica norteou o presente artigo. No Brasil, desde os anos 1980, há uma literatura consolidada sobre a "resistência enorme dos representantes de RH de compreender sua área de atuação como agente e resultado 
completo de relações sociais de trabalho" (Nogueira, 2002:119). Nessa resistência está implícita a percepção de que formação profissional não guarda sólidos vínculos com "movimento na sociedade", como propunha Naville.

Touraine (1988:171) percebeu, já na "sociedade programada" dos anos 1980 que "os laços do ensino com a atividade profissional tornam-se mais do que nunca estreitos, a tal ponto de não poder sequer separá-los". Os alunos do Centro Paula Souza convivem com a percepção de Touraine, mas constroem suas expectativas profissionais marcadas bem mais por outra premissa teórica: "a hierarquia da qualificação de trabalho é sempre mesclada a uma hierarquia social de funções" (Naville, 1956:12).

As hipóteses teóricas formuladas por Naville constituíram o ponto de partida para a investigação do primeiro núcleo da pesquisa. A questão de identificação de aspectos subjetivos, essência do segundo núcleo da pesquisa, também incluiu no plano epistemológico a análise da relação escola/trabalho, construída a partir da "recusa de qualquer tipo de determinismo tecnológico e econômico, que conduza a apresentar a escola como mero instrumento de qualificação, omitindo a circunstância de que, em suas atribuições sociais, a escola só participa de modo indireto da construção das qualificações" (Moraes, 2002:204). Se a escola não é mero instrumento de qualificação, a construção das motivações é, portanto, aspecto relevante nas escolhas profissionais.

A arquitetura das "motivações", com raiz teórica nos trabalhos de Maslow (1954:62), afirma que a satisfação pessoal possui uma ordem de predominância: "não teríamos o desejo de compor músicas ou criar sistemas matemáticos, ou estar bem vestidos se estivéssemos morrendo de sede". A partir dessa constatação, os objetivos humanos foram classificados "nas cinco necessidades que direcionam comportamentos e escolhas" (Maslow, 1954:90). A elaboração dos roteiros de entrevista para identificação dos aspectos subjetivos da pesquisa seguiu a proposta de Maslow e a análise de conteúdo dos resultados, porém, relativizou a sólida hierarquia dos desejos de Maslow pelo "modelo de entendimento dos processos motivacionais" propostos por Alderfer (1969). Esse autor identificou três níveis de necessidades - existência, relacionamento e crescimento - que combinam os cinco grupos de necessidades de Maslow. A leitura desses resultados, no entanto, também manteve a cautela de que "cada teoria apresentada possui uma visão da natureza humana" (Casado, 1998). Para essa autora, diferenças individuais exercem papel importante nas diversas visões sobre traços de personalidade como diferenciadores do comportamento e das escolhas humanas. Por essa vertente, foram incluídas "histórias de vida" na pesquisa.

A avaliação do equilíbrio entre conhecimento adquirido e exigido, base do terceiro núcleo da pesquisa, demandou um modelo teórico que assimilasse as 
duas extremidades dessa equação educacional, a sala de aula e o ambiente de trabalho. O modelo proposto por Meister (1999) definiu cinco etapas para captar a vantagem competitiva oferecida pela ação educacional e os compromissos da empresa para assimilar essa vantagem. Os tipos de "parceria entre empresa e escola" propostos pelo autor foram tipificados e adaptados à realidade da pesquisa.

A complexa questão da avaliação da "transferência de conhecimento" entre o laboratório da escola e a esteira de produção na empresa exigiu a inclusão do modelo de Parry (1997) para estabelecer "hierarquia de eficiência" nessa transferência de conhecimento. A eficácia no processo de treinamento da empresa, por sua vez, reutilizando o conhecimento oferecido pela escola, exigiu modelo específico de avaliação, adotando-se o de Kirkpatrick (1998). As entrevistas qualitativas com os responsáveis pela seleção e formação de mão-de-obra nas duas empresas escolhidas obedeceram ao modelo proposto por esse autor.

\section{Conteúdo da pesquisa}

\section{Primeiro núcleo}

A investigação sobre a origem da oferta de clientela para o ensino técnico foi iniciada com a realização de reuniões envolvendo os pesquisadores e o corpo diretivo das duas escolas - Martin Luther King e Professor Aprígio Gonzaga. As vagas oferecidas por esta última unidade são bastante concorridas, conforme dados da seleção para o primeiro semestre de 2004: para 440 vagas haviam 5.326 candidatos inscritos (12 candidatos por vaga). No caso específico do curso de eletrônica, a relação candidato/vaga é ainda maior: 16,38 candidatos por vaga. Na escola Martin Luther King, os cursos oferecidos apresentam igual concorrência, 11,9 candidatos por vaga, em média, e no curso noturno de mecatrônica, 13,5 candidatos por vaga.

Os alunos das escolas públicas das proximidades "que normalmente seriam atendidos por essas ETEs no caso da opção por um curso técnico" não têm presença significativa. Os dirigentes e coordenadores reconheceram a dificuldade de apontar alguma escola com maior incidência de ingressantes nas ETEs pesquisadas, o que evidencia a dificuldade de identificação do públicoalvo do Centro Paula Souza. Quanto ao perfil dos alunos ingressantes, as respostas dos dirigentes convergem na idéia de que não há um padrão. Os cursos técnicos são procurados tanto por jovens com necessidade de profissionalização para a viabilização do ingresso no mercado de trabalho quanto por adultos em situação de desemprego ou com necessidade de aprimoramento profissio- 
nal e de certificação para melhoria das condições de trabalho. A determinação da obrigatoriedade do cumprimento do curso regular para a obtenção da certificação técnica de nível médio "além da situação de desemprego" ocasionou a presença de grande quantidade de adultos nessas ETEs.

Foi possível constatar, na versão da coordenação, que o principal estímulo dos alunos para estudar, seja na Martin Luther King ou na Aprígio Gonzaga, é composto por três bases:

$\checkmark$ gratuidade da escola;

v imagem de eficácia na colocação do aluno no mercado de trabalho;

$\checkmark$ qualidade do ensino ministrado.

Da mesma forma, há o reconhecimento de que a "marca" Paula Souza é um referencial de qualidade sustentável. Boa parte da expectativa dos pais e dos alunos dos cursos de maior segmentação vem conectada com os padrões de eficiência implícitos nessa marca.

Quanto à importância do processo de seleção, nas duas escolas há a percepção de que, apesar da exclusão ocasionada pelo vestibulinho, é necessário democratizar a disputa por vagas e homogeneizar o nível dos alunos, aprimorando o nível do ensino oferecido.

\section{Entrevista com grupos de professores}

Quanto ao atendimento às expectativas dos alunos ingressantes, nas duas ETEs foi apontada como dificuldade principal a dicotomia entre prática e teoria. $\mathrm{Na}$ visão da maioria deles, os alunos começam o curso com a idéia de que os conceitos teóricos estariam em segundo plano pelo fato de terem ingressado em um curso técnico. Quanto à influência da escola básica na escolha por cursos do Centro Paula Souza, os professores das duas escolas entendem que as instituições escolares de ensino básico, principalmente as públicas, normalmente não influenciam a escolha e nem informam os alunos das possibilidades de cursos oferecidas.

\section{Resultado do levantamento da origem dos alunos por meio dos dossiês}

O levantamento da origem dos discentes foi efetuado por meio de pesquisa nos dossiês dos alunos. A amostragem foi feita pela seleção dos que estavam 
cursando o primeiro ciclo do ensino técnico no segundo semestre de 2003. Essa amostragem revelou, no caso da Martin Luther King, a concentração de apenas 6\% na E.E. Professor José Marques da Cruz e outros 6\% na E.E. Professor Oswaldo Catalano. A razão dessa concentração não é difícil de entender: a relativa proximidade com a referida ETE. Outras 12 escolas da rede oficial de ensino médio alcançaram até $2 \%$ do total de alunos ingressantes. O dado efetivamente relevante é que $62 \%$ das vagas foram preenchidas por alunos oriundos de 133 escolas diferentes, sendo apenas um aluno por escola.

No caso da Aprígio Gonzaga a amostragem revelou concentração de apenas 5\% na E.E. Professor Oswaldo Catalano e de outros 5\% na E.E.S.G. Professor Gabriel Ortiz. Outras 14 escolas concentraram até $2 \%$ do total dos alunos ingressantes. Porém, 58\% do total vieram de 174 estabelecimentos de ensino diferentes, sendo um aluno por escola.

A pesquisa revelou que a oferta de ensino profissional no âmbito público funciona como válvula de contenção e de exclusão social. Os educadores dos dois estabelecimentos repetem de forma incisiva que as escolas reúnem "a elite do ensino público". Portanto, repete-se no nível médio o fenômeno da universidade pública. O critério de seleção por mérito exclui da oferta de escolaridade profissionalizante a maioria da demanda. Isso indica que o estoque de habilidades ofertado pelos 11 anos de escolaridade fundamental e média do ensino público não é aproveitado, nem capacitado, para o exercício profissional. O hiato formado pelos "11 excluídos" — de cada 12 candidatos ao ensino profissionalizante só um obtém vaga - constrói o gap de capacitação que vitima o processo de produção na empresa brasileira.

\section{Segundo núcleo}

\section{Entrevista com coordenadores}

A influência das condições de infra-estrutura, apontada pelos coordenadores, é um condicionante importante de estímulo à demanda por cursos do Centro Paula Souza. Quanto à influência dos pais dos alunos no processo de escolha por um curso técnico, aspectos de localização têm alta importância, embora, para eles, o perfil curricular das instituições funcione como diferencial no mercado de trabalho.

Os coordenadores identificam que a construção de expectativas profissionais dos alunos está dividida em dois universos distintos. Para o período diurno, a informação e a expectativa sobre o mercado de trabalho estão mais concentradas na família que no jovem. No período noturno e nos cursos de 
profissionalização segmentada, como segurança no trabalho, por exemplo, a informação e a expectativa pertencem ao aluno. Essa diferença é essencial na definição não somente da trajetória escolar desses educandos, mas também na trajetória profissional, conforme apontaram os coordenadores.

\section{Entrevista com os professores}

No contato com os professores - indicados pelos coordenadores - o "sonho profissional" dos alunos começou a ser melhor identificado. É importante diferenciar o universo alcançado por cada umas das instituições a partir da distinção da clientela dos cursos oferecidos. Desse modo, os professores da área de "turismo", por exemplo, observaram que remuneração salarial para os alunos do curso inclui "o sonho da viagem". Essas remunerações "complementares" estão presentes na constituição mais elementar do que é a expectativa profissional dos educandos. Os professores identificam também que "realização pessoal" se mistura com essas perspectivas simplistas do mercado de trabalho. Quanto à percepção de acesso real ao mercado de trabalho, os professores identificaram a formação de um conceito de empregabilidade no corpo discente.

\section{Expectativas identificadas}

Essas foram as expectativas identificadas:

\ ganhar dinheiro - nos cursos diurnos, os professores de modo unânime apontam a confusão entre "ganhar dinheiro" e a conquista de um bom emprego. Nos cursos noturnos ou de alcance segmentado os professores apontam a clara percepção de que a conclusão do curso implica sobrevivência;

v melhor posição social - para os professores, no caso do diurno, os alunos confundem status com conquista de postos de trabalho em grandes empresas. Nos alunos do noturno, a posição social está vinculada à conquista de posto de trabalho na economia formal. Não foi identificada nenhuma distinção em relação ao tamanho da empresa;

v mercado de trabalho - curiosamente, os professores registram entre os alunos do diurno a percepção do risco do não-emprego, justificado por um maior acesso à informação quanto às condições econômicas do país. No caso do noturno, os professores registram a óbvia percepção dos alunos quanto à restrição de oferta individual de trabalho, do tipo "não há emprego para 
alguém com a minha formação". Tal constatação, relatada pelo professores, implica um tipo determinado de expectativa quanto ao curso, mais segmentada, mais vinculada a tipificações e ocupações das empresas.

\section{Entrevista com os alunos}

Para manutenção do teor das observações dos professores, procuramos manter a mesma forma esquemática na apresentação do conteúdo de expectativas identificadas pelos alunos:

V ganhar dinheiro - no curso de turismo, os alunos confirmam a impressão do corpo docente. Há uma confusão entre "ganhar dinheiro viajando" e "ter um bom emprego". Nos cursos noturnos foi possível identificar com bastante clareza que há limites muito bem definidos nesse tipo de expectativa, os alunos têm a exata consciência dos padrões salariais que podem alcançar e falam disso com naturalidade, reconhecendo que a certificação da escola técnica tem peso na manutenção do trabalho;

- melhor posição social - a observação dos professores foi confirmada; os alunos confundem status com conquista de postos de trabalho em grandes empresas. Entre os alunos do noturno, foi preciso repetir com palavras diferentes a tentativa de abrir o debate sobre posição social. A impressão que ficou é que esse tipo de preocupação não se consolida entre estes últimos;

- mercado de trabalho - os alunos do curso diurno têm uma percepção maior do risco do desemprego, apesar da certificação oferecida pelo curso técnico. O quadro é diferente com o noturno. Há clareza quanto a esses espaços e oportunidades; os contornos do mercado têm melhor definição para esses alunos, embora tenham limites muito precisos quanto a ambições salariais;

- emprego de qualidade - para o aluno do diurno foi possível identificar mais claramente que o "sonho" de trabalhar em uma grande empresa é quase um denominador comum, embora essa expectativa não tenha maior clareza. Há uma repetição em torno das qualidades do trabalho na "grande empresa" com a mesma intensidade com que ocorre a percepção de que "a realidade é que as oportunidades estão nas pequenas empresas";

v empreendedorismo - a hipótese de abertura do "próprio negócio" é uma expectativa da minoria. Foi possível identificar que há um relativo, para não dizer insignificante, desejo de empreender entre os alunos do diurno, mesmo no curso de eletrônica. Entre os alunos do noturno a tendência para 
um mínimo empreendedorismo é mais visível, embora tenha sido difícil identificar com exatidão o que a expressão "negócio próprio" quer efetivamente dizer para o aluno que a usa.

\section{Terceiro núcleo}

A investigação sobre a capacitação da clientela da escola técnica desfocada do exercício profissional foi feita com a realização de reuniões envolvendo o corpo diretivo, professores e ex-alunos das duas escolas pesquisadas, além de contatos com o corpo técnico das empresas selecionadas, NET Brasil e Telefônica São Paulo.

\section{Histórias de vida}

Professores indicados pela direção foram procurados para descrever as "histórias de vida" dos egressos de que tinham conhecimento. Além disso, os arquivos das secretarias das duas escolas forneceram uma lista de egressos que auxiliaram na recuperação de contatos. Dessa forma, foi possível formar um grupo de observação.

\section{Entrevistas com professores}

Na Aprígio Gonzaga, os educadores, particularmente os da área de eletrônica, listaram nomes de egressos a partir de algumas escolhas profissionais bem-sucedidas. Alguns professores reconheceram a dificuldade de acompanhar os passos dos ex-alunos. Porém, com a colaboração de professores "orientadores de estágio", foi possível reconstruir parte da trajetória desses egressos. Os professores procuraram concentrar em algumas empresas as indicações dos ex-alunos. Foi possível, portanto, estabelecer que no período de seis a oito anos atrás a indústria automotiva, em especial a Volkswagen do Brasil concentrava - conforme as indicações do arquivo de estágio e da memória dos professores - a maior parte das trajetórias de sucesso dos egressos daquela unidade do Centro Paula Souza. No período entre quatro e seis anos atrás, empresas específicas do setor de telecomunicações (Siemens, por exemplo) representavam o foco de atenção dos alunos dessa unidade. Como as listagens de estágio e a memória dos educadores podem confirmar, nos últimos quatro anos ocorreu exagerada concentração de estágios e, portanto, prováveis futuras trajetórias profissionais, em empresas 
prestadoras de serviço. A clássica terceirização que atingiu o setor de telefonia - caso da Embratel e da Telefônica - absorveu boa parte das aspirações dos que, na memória dos professores, alcançaram colocação profissional.

É possível identificar por esse tipo de descrição e de avaliação por amostragem no setor de estágios que os egressos dessa escola estão construindo suas trajetórias profissionais não mais na indústria de transformação do setor eletroeletrônico, mas no setor de serviços das grandes empresas privatizadas desse setor.

Os professores insistiram em uma observação específica: no caso dos alunos do período da tarde, a memória desses educadores registra - confirmado pelas fichas de estágio - que as trajetórias dos egressos indicavam um esvaziamento de expectativas profissionais. Apesar da cautela revelada pelos professores, é possível perceber que a expectativa dos alunos do período da tarde passou a ser predominantemente a universidade e não mais o mundo do trabalho.

Na Martin Luther King, por indicação da direção, o escolhido para colaborar diretamente na indicação de egressos foi o professor coordenador do estágio. Essa especificidade produziu outra perspectiva dessas trajetórias profissionais. A condição do coordenador de estágio implicou uma valorização dessa etapa da formação profissional e outro tipo de vínculo com o egresso do Centro Paula Souza: o coordenador de estágio assumia, com cautela mas com decisão, o papel de orientador de carreira. Esse profissional conduziu suas observações apoiado no SAI (sistema de avaliação institucional). Esse tipo de observação gerou uma perspectiva macroeducacional dos egressos da instituição, privilegiando aspectos de formação cognitiva que despertavam, impulsionavam ou apenas permitiam futuros desenvolvimentos de carreira, não necessariamente em áreas diretamente afins ao curso concluído. A pertinência da observação pôde ser confirmada na diversidade da oferta de estágio, sinalizando expectativas mais amplas de colocação profissional, multidisciplinares, desconcentrando expectativas.

\section{Grupos de observação qualitativa com egressos da Aprígio Gonzaga}

Com a ajuda de funcionários da escola e de alguns professores foi possível formar um reduzido grupo de ex-alunos da unidade para uma pesquisa qualitativa sobre suas trajetórias profissionais. Foram selecionados dois focos para concentrar as discussões do grupo. O primeiro deles referia-se ao imediato pós-curso: da expectativa à realização, o que ocorreu no primeiro ano após a conclusão do curso profissionalizante. O segundo foco concentrou-se na atual profissionalização desses ex-alunos, desprezando-se o hiato entre um foco e outro. 
Há aí um ponto comum a ser destacado: a realização de estágio no final do curso e os salários oferecidos para o aluno diplomado representavam uma perda sensível de poder aquisitivo. De modo geral, esses egressos insistiam que o período pós-conclusão do curso continuava a ser "fase de investimento" no futuro profissional. Investigando-se mais esta expressão foi possível entendêla melhor: ao longo do período escolar, segundo a observação desse reduzido grupo, o trabalho em áreas não relacionadas ao curso redundava em rendimento superior - significativamente superior, segundo alguns deles - ao recebido em estágios ou em primeira colocação em empregos em áreas diretamente afins ao curso concluído. A provocação do pesquisador quanto ao papel representado pelo laboratório da escola como "instigador" para um vínculo profissional com áreas afins foi rejeitado pelo grupo. De modo geral, os exalunos mencionavam a fragilidade técnica do laboratório e das reformas neles ocorridas como obstáculos para essa vivência profissional.

É obrigatório notar que parte do grupo de observação mencionou que o curso concluído colaborou "no desenvolvimento da carreira", curiosamente nem sempre vinculada à área cursada. Esse reconhecimento da validade do curso sustentava uma expectativa de continuidade educacional e, nesse caso, nesse grupo qualitativo, essa continuidade previa ingresso em curso superior. Não foi possível identificar uma área de concentração para essa expectativa de educação superior, mas o pesquisador registrou a inexistência de expectativa em torno do curso de tecnólogo.

\section{Entrevistas com a direção e coordenação}

O objetivo da pesquisa relativa aos vínculos entre condições de ensino e realidade profissional incluiu a análise dos diferentes fatores que facilitavam ou prejudicavam a inserção dos egressos das duas unidades pesquisadas no mercado de trabalho. O ponto de partida para essa identificação foi o contato com a direção e a coordenação das duas escolas.

$\mathrm{Na}$ visão do corpo diretivo da escola Aprígio Gonzaga, os problemas do egresso com o trabalho começam pela equivocada percepção de parcela considerável dos alunos, que atribui à escola a tarefa de obter espaço no mercado. A viabilização desse objetivo de colocação profissional passa a ser, na visão desses educandos, uma espécie de "responsabilidade básica" do próprio currículo do curso escolhido. A direção da unidade insiste que há forte incentivo para um primeiro contato com o mercado de trabalho pelo encaminhamento para estágio, tanto nas empresas da região quanto por meio de órgãos como o Centro de Integração Empresa-Escola (Ciee) e Núcleo Brasileiro de Estágios 
(Nube). A coordenação da unidade, por sua vez, apontou para um detalhe importante no processo de inserção no mercado de trabalho via estágio: a relevância e as diferentes eficácias dessa inserção conforme a faixa etária.

A coordenação explicou que alunos de idade mais avançada enfrentam problema de desemprego e não de inserção no mercado de trabalho. Para a coordenação, a trajetória profissional do egresso depende, em grande parte, de sua faixa etária. A eficácia do curso ou da escola quanto à inserção profissional obedece a um fator imponderável: a idade do educando. Como não há restrição por faixa etária no processo de seleção, é difícil avaliar ou vincular os resultados finais da trajetória escolar apenas pela maior ou menor facilidade de colocação no mercado de trabalho.

A direção chamou a atenção também para a pertinente observação de que a remuneração oferecida ao egresso da escola no primeiro emprego póscertificação, normalmente não é compatível com a necessidade financeira dos alunos de maior faixa etária. A frustração de expectativas quanto ao conteúdo de cursos tem um arco de ponderações que não pode estar subordinada exclusivamente a fatores internos do processo educativo profissionalizante. Observe-se, por exemplo, que o curso de secretariado, que tem o menor índice de evasão entre todos os cursos e o maior aproveitamento no mercado de trabalho, reúne a maior homogeneidade de oferta no perfil da clientela.

Na Martin Luther King, em contato semelhante, a coordenação apontou outro fator como obstáculo para o vínculo do mercado de trabalho do egresso. Em certos casos, como no curso de mecânica industrial, é preciso observar o "envelhecimento da estrutura produtiva" no setor de atividade, que provoca um impacto negativo na oferta dos postos de trabalho. Esse fator causa uma sensível migração desses alunos para o curso de mecânica automobilística. Novamente, se pode notar que interferências externas inviabilizam aproveitamento maior do egresso dessas unidades no mercado de trabalho.

Conforme orientação recebida pela direção dos dois estabelecimentos, a pesquisa centrou atenção em dois centros receptores da mão-de-obra egressa dessas escolas: Telefônica e NET.

\section{Contato com as empresas}

\section{Centro de recepção: Telefônica}

A pesquisa foi feita com um grupo de funcionários da Telefônica incumbidos de seleção de pessoal para avaliação da trajetória dos egressos do ensino profissionalizante na companhia. Foi possível identificar que a primeira forma 
de contato para postos de trabalho na Telefônica não é o vínculo com escolas específicas e sim o acesso ao site da empresa, que permite a inserção de currículo. Os funcionários da Telefônica reconheceram que apenas quando não encontram profissionais nessa base de currículos do site é que divulgam em escolas técnicas a disponibilidade de vagas.

A trajetória de um egresso de escola de nível técnico acompanha as avaliações de desempenho comuns a qualquer estagiário na primeira fase de sua contratação, segundo a observação desses funcionários. Há uma constatação que não se sustenta em dados estatísticos — pelo menos até o momento — de que escolas que apresentam bons conceitos no mercado detêm uma espécie de preferência no momento da escolha. A empresa não opera e não aceita qualquer tipo de ranking entre as escolas profissionalizantes, mas é inquestionável que há uma espécie de "critério seletivo" a partir do nome de alguns estabelecimentos.

O peso da formação técnica na contratação tem vínculo direto com o perfil de atuação do profissional contratado. É importante observar que o grupo de funcionários de seleção de pessoal da Telefônica definiu como primeira característica desejada no processo seletivo "força de vontade e interesse em aprender" e não qualquer especificidade de formação técnica. Quanto à intervenção dessa formação técnica nas expectativas de carreira, o grupo de funcionários reconheceu que "depende mais das oportunidades" do que da formação técnica para qualquer avanço ou retardo nessa evolução.

A pergunta sobre a necessidade de treinamento de um contratado que apresenta certificação de ensino técnico foi respondida de forma enfática: há um período básico, obrigatório, de conhecimento da cultura da empresa e dos processos, que é de três meses e que independe da formação prévia do contratado. Portanto, contratados com certificação de ensino técnico, na Telefônica, não estão excluídos dos ciclos de treinamento da empresa. A empresa não reconhece deficiência nesses profissionais, mas reconhece que processos de treinamento são necessários e obrigatórios.

\section{Centro de recepção: NET}

Nessa companhia, como na Telefônica, o processo de seleção obedece a um banco de currículos, preferencialmente. Porém há uma diferença: na NET, a divulgação de vagas em aberto nas escolas profissionalizantes somente ocorre em "momentos de grande contratação". Também não há nenhum ranking que privilegie determinada escola profissionalizante, mas os critérios de contratação obedecem a certos limites no perfil de formação técnica. Conforme explicou a 
responsável pela área de gestão de pessoas: "temos um teste de conhecimentos básicos em eletrônica, pois acreditamos que se um profissional passou quatro anos no curso técnico, alguns conhecimentos devem estar sedimentados e isso facilitará a assimilação e aprendizado dos conteúdos específicos do nosso negócio". É uma atitude para contratação diferente da praticada na Telefônica.

A formação técnica é encarada na NET como pré-requisito para a participação e continuidade no processo de seleção. Porém, é preciso notar que os funcionários da NET reconheceram que todos os novos colaboradores passam por um processo de treinamento tanto em equipamentos técnicos quanto de atendimento e de produtos, com prazos variados porque o negócio requer "conhecimentos técnicos e padrões específicos". Os funcionários da NET evitaram comentar o tipo de exigências de conhecimento técnico que fazem em seus testes de seleção.

\section{Conclusões}

O primeiro pilar do universo subjetivo dos alunos das escolas técnicas selecionadas é a própria escolha do Centro Paula Souza como uma "grife" de importância reconhecida para a inserção na vida profissional. A escolha da instituição é decisão que carrega forte carga imaginária no jovem. A clientela que procura o processo de seleção do Centro Paula Souza intui, antes de entrar na escola, que a oferta educacional que irá receber tem demanda garantida no mercado. Depois de ingressar na escola, esse imaginário do jovem sofre um processo de consolidação e de reversão de expectativas. Ao longo da trajetória do aluno pela escola, outros fatores, igualmente subjetivos, irão influenciar as escolhas profissionais.

O segundo pilar do universo subjetivo é a satisfação profissional. O aluno de escola técnica se vê como uma "elite" melhor preparada para enfrentar as disputas no mercado profissional. Portanto, a conquista de um posto de trabalho não precário, no setor de atividade compatível com o curso escolhido, é uma expectativa consolidada. Esse critério define um conceito de satisfação profissional que também implica grupos de expectativas: faixa salarial, ambiente privilegiado de trabalho, capacidade empreendedora e oportunidades de liderança. Tais fatores têm peso específico no conceito de satisfação profissional desse jovem.

O terceiro pilar da subjetividade está na identificação do grau de empregabilidade implícito nas potencialidades agregadas ao diploma do Centro Paula Souza. A chegada do jovem ao mundo do trabalho não está mais circunscrita à atividade produtiva. Os alunos da instituição têm um conjunto de ambições que superam o perfil de formação técnica profissionalizante que 
receberam. Eles se veêm como "engenheiros em formação" desde o primeiro ano da escola e têm um conjunto de ambições novas e não compatíveis com as classificações de expectativas nas duas últimas décadas. A evolução das tecnologias e a democratização do acesso a elas são os primeiros aspectos dessas mudanças na classificação de expectativas.

\section{Formações técnicas e políticas públicas}

Após a pesquisa, ficaram definidas cinco observações diretivas em relação a políticas públicas de formação de mão-de-obra técnica:

v na oferta de escolaridade profissionalizante, o critério de seleção por mérito exclui a maioria da demanda - de 12 candidatos a um processo seletivo de capacitação profissionalizante em escola técnica, só um obtém a oportunidade. Não foi possível medir o prejuízo que esse gap de capacitação gera nos índices de produtividade das empresas que demandam mão-de-obra com esse nível de escolaridade;

as trajetórias dos egressos das políticas públicas de formação profissional indicam o esvaziamento de expectativas profissionais, de modo unânime, professores descrevem que as melhores vocações técnicas migram suas expectativas do mundo do trabalho para a universidade;

as políticas públicas direcionadas para a valorização do estágio como etapa de formação profissional têm menor eficiência do que a adoção de professores que assumem o papel de orientadores de carreira;

as políticas públicas insistem na "equivocada percepção" (visão dos professores) que atribui à escola profissional a tarefa de obter espaço no mercado de trabalho. Essa responsabilidade básica diminui, na visão dos educadores, o potencial de empregabilidade do educando;

v a não-atenção das políticas públicas à faixa etária do educando no processo de seleção - o histórico da colocação no mercado de trabalho sinaliza uma relação de custo/benefício muito maior das faixas etárias que se mantêm na relação apropriada idade/série.

\section{Depois da escola}

Nas empresas de tecnologia de ponta do setor eletroeletrônico, o recrutamento de pessoal prioriza a capacidade do candidato de raciocinar logicamente. A 
habilidade adquirida na escola técnica de padrão médio (quando é o caso) ou no ensino profissionalizante não é mais fato essencial do processo de recrutamento de mão-de-obra especializada. Cada vez mais é valorizado, nesse tipo de contratação, o profissional com bons conhecimentos em lógica, matemática e probabilidade.

O fato sugere que o ensino profissional não acompanha a evolução das áreas de tecnologia das grandes empresas. A agilidade dos investimentos e a concorrência entre as grandes empresas do setor agravam a distância entre a oferta de qualificação das instituições de ensino e a demanda real do mercado de trabalho. As empresas do setor eletroeletrônico contratam jovens conscientes da necessidade de completar sua formação com cursos rápidos, específicos, que ofereçam capacitação técnica básica para integrá-los às suas linhas de produção.

Uma primeira observação do conteúdo programático das escolas selecionadas indica que a carreira de técnico em telecomunicações, por exemplo, requer (além das disciplinas obrigatórias do chamado núcleo comum) noções de eletrônica geral, eletrônica digital e eletricidade para oferecer suporte para as demais disciplinas técnicas do curso. Um curso como telecomunicações e eletrônica parte de plataformas semelhantes de conhecimentos básicos. Entre essa formação curricular e a capacidade de instalar, operar e dar manutenção a sistemas de rádio-comunciação, de telefonia (fixa e móvel), comunicação de dados e infra-estrutura de centrais telefônicas de uma empresa como a Telefônica de São Paulo, há respeitável hiato técnico entre o que é a demanda da empresa e o que é a oferta de capacitação da escola técnica.

\section{Referências bibliográficas}

ABRAMOVAY, M. (Coord.). Abrindo espaços - avaliação do programa. Brasília: Unesco/ Universidade Católica de Brasília, 2003.

ALDERFER, C. An empirical test of a new theory of human needs. Organizational behavior and human performance, May 1969.

BARDIN, L. Análise de conteúdo. Lisboa: Edições 70, 2003.

BÊRNI, D. A. (Org.). Técnicas de pesquisa em economia: transformando curiosidade em conhecimento. São Paulo: Saraiva, 2002.

BOVESPA. Perfil do jovem universitário paulistano - 2000. São Paulo: Bovespa, 2000.

BUENO, M. S. S. Políticas inclusivas, diretrizes e práticas excludentes: o ensino médio na 
perspectiva da educação básica. In: ZIBAS, D.; AGUIAR, M.; BUENO, M. S. (Orgs.). O ensino médio e a reforma da educação básica. Brasília: Plano, 2002.

CASADO, T. Tipos psicológicos: uma proposta de instrumento para diagnóstico do potencial humano nas organizações. 1998. Tese (Doutorado) - FEA/USP, São Paulo.

CASTRO, M. G. (Coord.). Cultivando vida, desarmando violências - experiências com cultura, lazer e cidadania com jovens. Brasília: Unesco, 2001.

DEPARTMENT FOR EDUCATION AND EMPLOYMENT. Labour market \& skill trends. Londres, 1998.

FILMUS, D. A educação média diante do mercado de trabalho: cada vez mais necessária, cada vez mais insuficiente. In: BRASLAVSKY, C. (Org.). Educação secundária: mudança ou imutabilidade? Brasília: Unesco, 2002.

GIL, A. C. Métodos e técnicas de pesquisa social. São Paulo: Atlas, 1999.

GOIS, Antonio. Aluno da rede pública foge do vestibular. Folha de S. Paulo, Caderno Folha Cotidiano, 18 ago. 2002.

INSTITUTE FOR EMPLOYMENT RESEARCH. Modern apprenticeships: a survey of employers. Londres: RS53, H M Stationery Office, 1997.

INSTITUTE OF PERSONNEL AND DEVELOPMENT. Overqualified \& underemployed. IPD Survey Report. Londres: Institute of Personnel and Development, Aug. 1997.

KIRKPATRICK, D. L. Evaluating training programs: the four levels. Alexandria: ASTD, 1998.

KUENZER, A. Z. (Org.). Ensino médio: construindo uma proposta para os que vivem do trabalho. São Paulo: Cortez, 2002.

LAKATOS, E. M.; MARCONI, M. Metodologia do trabalho científico: procedimentos básicos, pesquisa bibliográfica, projeto e relatório, publicações e trabalhos científicos. São Paulo: Atlas, 1992. . Metodologia do trabalho científico. São Paulo: Atlas, 1998. ; __ Fundamentos de metodologia científica. São Paulo: Atlas, 2000.

MASLOW, A. H. Motivation and personality. New York: McGraw-Hill, 1935.

MEISTER, J. Educação corporativa. São Paulo: Makron Books, 1999.

. Building a learning organization: 7 lessons to involve your CEO. Lincoln: iUniverse.com, Inc., 2001. 
MORAES, C. S. V. O ensino técnico, a formação profissional e o mundo do trabalho: algumas questões de método. In: O ensino médio e a reforma da educação básica. Brasília: Plano, 2002.

MOREIRA, D. A. O método fenomenológico na pesquisa. São Paulo: Pioneira Thomson, 2002.

MORIN, E. A educação e a complexidade do ser e do saber. Petrópolis: Vozes, 2001.

NAVILLE, P. Essai sur la qualification du trvail. Paris: Gallimard.

Gallimard, 1963.

Vers l'automatisme social? Problèmes du travail e de l'automation. Paris:

NOGUEIRA, A. J. F. Gestão estratégica das relações de trabalho. In: FLEURY, M. T. L. As pessoas na organização. São Paulo: Gente, 2002.

PAIS, J. M. Culturas juvenis. Lisboa: Imprensa Nacional/Casa da Moeda, 1996.

. Ganchos, tachos e biscates: jovens trabalho e futuro. Porto: Âmbar, 2001.

PARRY, S. B. Evaluating the impact of training. Alexandria: ASTD, 1997.

POCHMANN, M. A batalha pelo primeiro emprego. São Paulo: Publisher Brasil, 2000.

RICHARDSON, R. J. et al. Pesquisa social: métodos e técnicas. São Paulo: Atlas, 1999.

SELLTIZ, C. et al. Métodos de pesquisa nas relações sociais. São Paulo: Herder, 1967.

; KIDDER, L. H. (Orgs.). Métodos de pesquisa nas relações sociais. Delineamentos de pesquisa. São Paulo: EPU, 1987. v. 1.

SEADE, F. E. A. D. 20 anos no ano 2000, estudos sociodemográficos da juventude paulista. São Paulo: Fundação Seade/Secretaria de Economia e Planejamento, 2001.

TESCH, R. Qualitative research, analisys types and software tools. Bristol: The Farmer Press, 1990.

TOURAINE, A. O pós-socialismo. São Paulo: Brasiliense, 1988.

TREVISAN, L. N. Jovens, mentiras e desemprego - algumas incertezas sobre a oferta educacional como receita de felicidade. In: DOWBOR, L. et al. (Orgs.). Desafios do trabalho. Petrópolis: Vozes, 2004. 